\title{
Comparison of four different solid-phase microextraction fibers for analysis of Plectranthus amboinicus (Lour.) Spreng. leaf volatiles
}

\section{Guilherme Perez Pinheiro ${ }^{1 *}$, Maria Isabel Galbiatti ${ }^{1}$, Mara Junqueira Carneiro ${ }^{1}$ and Alexandra Christine Helena Frankland Sawaya ${ }^{2}$}

${ }^{1}$ Department of Plant Biology, Institute of Biology, University of Campinas, São Paulo, Brazil.

${ }^{2}$ Faculty of Pharmaceutical Sciences, University of Campinas, São Paulo, Brazil.

Accepted 17 April, 2019

\begin{abstract}
Plectranthus amboinicus, also known as Indian borage or Mexican mint, is a species of Lamiaceae cultivated worldwide for ornamental, culinary and medicinal purposes, being used in folk medicine for the treatment of respiratory diseases and digestive problems. These properties are attributed to the abundance of phenolic monoterpenes present in its essential oil, which have been extensively described in the literature. The low yield of essential oil hinders further investigation, besides the extraction being a costly and time-consuming procedure. The application of headspace-solid-phase microextraction (HS-SPME) coupled to gas chromatography-mass spectrometry (GC-MS), an alternative technique in plant volatile analysis, is described in the present study for $P$. amboinicus growing in Brazil. Four SPME fibers with different coating composition were evaluated: polydimethylsiloxane (PDMS - $100 \mu \mathrm{m}$ ), carboxen/polydimethylsiloxane (CAR/PDMS - $75 \mu \mathrm{m}$ ), divinylbenzene/carboxen/polydimethylsiloxane (DVB/CAR/PDMS - 50/30 $\mu \mathrm{m}$ ) and polydimethylsiloxane/divinylbenzene (PDMS/DVB - $65 \mu \mathrm{m}$ ). PDMS fiber extracted a total of 19 identified compounds $(52.46 \%$ of monoterpenes and $42.09 \%$ of sesquiterpenes), CAR/PDMS fiber 22 identified compounds (55.05\% of monoterpenes and $25.51 \%$ of sesquiterpenes), DVB/CAR/PDMS fiber 24 identified compounds (67.22\% of monoterpenes and $23.88 \%$ of sesquiterpenes) and PDMS/DVB fiber 26 identified compounds (64.3\% of monoterpenes and $30.93 \%$ of sesquiterpenes). The extractions with PDMS/DVB and DVB/CAR/PDMS fibers resulted in similar chemical profiles when compared to essential oil composition, in particular the triple-coated DVB/CAR/PDMS fiber which extracted more compounds with high retention time. Both of these fibers are the most suitable in an untargeted analysis of $P$. amboinicus volatiles, while PDMS and CAR/PDMS may be suitable for target compounds or classes of compounds. The data reported in this study demonstrates that HS-SPME coupled to GC-MS is a rapid and simple method of analysis and compose a valuable tool for the study of $P$. amboinicus volatiles.
\end{abstract}

Keywords: Medicinal plant, headspace volatiles, essential oil, gas chromatography-mass spectrometry, Plectranthus amboinicus.

*Corresponding author. E-mail: pinheiro.gperez@gmail.com. Tel: +55 19 3521-6219.

\section{INTRODUCTION}

Plectranthus amboinicus (Lour.) Spreng. also known as Indian borage or Mexican mint, is a perennial, succulent and strongly aromatic herb used in folk medicine for the treatment of respiratory diseases and digestive problems (Lukhoba et al., 2006). Characterized by its oregano-like odor and flavor, the species probably originated in Africa or India and it has since become widely distributed around the world for ornamental, medicinal and culinary purposes (Codd, 1975; Lorenzi and Matos, 2008; Arumugam et al., 2016). The therapeutic properties of $P$. amboinicus extracts are related to various biological activities, such as antimicrobial, antioxidant and antiinflammatory (da Costa et al., 2010; Swamy et al., 2017; Chiu et al., 2012). These properties are speculated to be 
due to phenolic monoterpenes (i.e. thymol and carvacrol) present in the essential oil of the species (Singh et al., 2002; Gavaric et al., 2015; Lee et al., 2017) and other minor components such as $p$-cymene, $\gamma$-terpinene, $\beta$ caryophyllene and $\alpha$-humulene (da Costa, 2010). Other bioactivities have been attributed to $P$. amboinicus essential oil, such as the larvicidal potential against medically important Diptera vectors, and are indicated as possible alternative uses (Senthilkumar and Venkatesalu, 2010; Lima et al., 2011).

$P$. amboinicus phytochemistry has been largely investigated with emphasis on essential oil composition. Arumugam et al. (2016) indicated a total of 76 volatile compounds occurring in the essential oil, particularly rich in oxygenated monoterpenes. Although the composition of this oil has been vastly described in the literature, the low yield makes extensive approaches difficult, such as metabolomics, owing to the need of huge amounts of crude material (Bezerra et al., 2017). Furthermore, sample preparation is a costly and time-consuming procedure in which the plant material is subjected to water at high temperatures or organic solvents (Charles and Simon, 1990), with possible degradation of unstable compounds. Recent trends in analytical chemistry lean towards simplification of sample preparation and waste minimization. Over the last few decades, solid-phase microextraction (SPME) has been introduced as an alternative technique in the analysis of plant volatiles due to integration of sample extraction, concentration and transfer into GC injector (Zhang and Pawliszyn, 1993). This process allows automation of the sample preparation step and consequently shortens the time of analysis. Headspace analysis via SPME (HS-SPME) has been applied for metabolic profiling and metabolomic studies of many plant species (Belliardo et al., 2006), however few have evaluated the volatiles of the genus Plectranthus utilizing this technique (Passinho-Soares et al., 2013; von Oppen et al., 2015; El-Sakhawy et al., 2018; Camelo et al., 2019).

The present study was carried out to evaluate four different SPME fiber assemblies and determine their uses in $P$. amboinicus volatile profiling through HS-SPME coupled to gas chromatography-mass spectrometry (GC$M S)$. The chosen fibers presented distinct coating composition, potentially covering a wide range of polarity and molecular weight compounds in the extraction process. The chemical composition was described for each fiber assembly and the GC-MS profiles were compared between fiber types. Besides HS-SPME analysis, essential oil from $P$. amboinicus leaves was extracted and analyzed in order to compare this traditional method of extraction with HS-SPME.

\section{MATERIALS AND METHODS}

\section{Plant material}

Fresh leaves of $P$. amboinicus were collected in July 2018 from plants growing at the Experimental Field of the Institute of Biology, University of Campinas (São Paulo, Brazil). A voucher specimen has been deposited in the Herbarium of the University of Campinas (UEC 201378). The leaf samples were immediately frozen with liquid nitrogen for metabolic quenching after collection and ground into a fine powder while frozen for further extraction of the headspace volatiles and essential oil.

\section{Headspace solid phase microextraction (HS-SPME)}

Frozen ground leaves of $P$. amboinicus $(0.50 \mathrm{~g})$ were transferred to $20 \mathrm{ml}$ SPME vials, which were immediately closed and stored at $80^{\circ} \mathrm{C}$ until the extraction. Each vial was incubated at $50^{\circ} \mathrm{C}$ for 5.00 min and the HS-SPME was conducted at this temperature for 10.00 min using one of four fiber assemblies: polydimethylsiloxane (PDMS - $100 \mu \mathrm{m}$ ), carboxen/polydimethylsiloxane (CAR/PDMS - 75 $\mu \mathrm{m}$ ), divinylbenzene/carboxen/polydimethylsiloxane (DVB/CAR/ PDMS - 50/30 $\mu \mathrm{m}$ ) and polydimethylsiloxane/ divinylbenzene (PDMS/DVB - $65 \mu \mathrm{m}$ ) obtained from Supelco, Bellefonte, PA, USA. All fiber assemblies were tested in triplicate. A HS-SPME was performed for each fiber assembly utilizing an alkane standard solution (C8 - C20, Sigma-Aldrich), enabling the calculation of the retention index.

\section{Essential oil extraction and dilution}

The essential oil of $P$. amboinicus leaves was extracted by hydrodistillation using a Clevenger-type apparatus. The extraction proceeded for $4 \mathrm{~h}$, time required to cease essential oil acquisition, and the oil was subsequently stored in amber vials at $-80^{\circ} \mathrm{C}$. The essential oil was diluted in dichloromethane $(1: 10 \mathrm{v} / \mathrm{v})$ for chromatographic analysis, which was performed in triplicate.

\section{Chromatographic analysis}

The GC-MS analyses were performed on an Agilent Model 7890A GC System (Agilent Technologies, CA, USA) fitted with a HP-5ms fused silica capillary column (Agilent J\&W, USA - $30 \mathrm{~m} \times 0.25 \mathrm{~mm} \times$ $0.25 \mu \mathrm{m}$ film thickness) and coupled to an Agilent Model 5975C inert MSD with Triple-Axis Detector (Agilent Technologies, CA, USA). The following GC-MS operating conditions were used for essential oil analysis: injector temperature at $220^{\circ} \mathrm{C}$, transfer line at $240^{\circ} \mathrm{C}$, oven program from $60^{\circ} \mathrm{C}$ up to $246^{\circ} \mathrm{C}$ at $3^{\circ} \mathrm{C} / \mathrm{min}$, carrier gas used was He at $1.00 \mathrm{ml} / \mathrm{min}$, injection volume of $1 \mu \mathrm{l}$ and split ratio of 1:50; the solvent delay was $2.00 \mathrm{~min}$ and the mass spectrometer acquisition mode was full scan $(40-500 \mathrm{~m} / \mathrm{z})$. An alkane standard solution (C8 - C20, Sigma-Aldrich) was analyzed in the same conditions to calculate the retention index. Previous tests with the SPME fibers (data not shown) exhibited no chromatographic peaks after $35 \mathrm{~min}$, thus the previously described operating conditions were adapted, in order to shorten the chromatographic run: oven program from $60^{\circ} \mathrm{C}$ up to $165^{\circ} \mathrm{C}$ at 3 ${ }^{\circ} \mathrm{C} / \mathrm{min}$ then up to $210^{\circ} \mathrm{C}$ at $15^{\circ} \mathrm{C} / \mathrm{min}$, desorption time of $900 \mathrm{~s}$, splitless mode and without solvent delay. Chemical compounds were identified through mass spectra comparison with NIST Library and retention index comparison with Adams (2007).

\section{RESULTS AND DISCUSSION}

HS-SPME/GC-MS analyses of $P$. amboinicus leaf volatiles were conducted using four fiber assemblies. The major headspace components were present in all chemical profiles, but their area percentage varied 
between different fibers (Figure 1). The PDMS fiber chromatogram displayed few compounds with low retention time (before $7 \mathrm{~min}$ ) as opposed to the CAR/PDMS fiber chromatogram which presented the highest abundance of these components. PDMS/DVB and DVB/CAR/PDMS fibers resulted in similar GC-MS chemical profiles, although the DVB/CAR/PDMS fiber extracted more compounds with high retention time (after $30 \mathrm{~min}$ ) in comparison with PDMS/DVB fiber.

A total of 28 compounds were identified according to their mass spectra and retention indices by comparison to databases (Table 1). The essential oil extraction yield was approximately $0.01 \%(\mathrm{~m} / \mathrm{m})$ and the major component was carvacrol with $47.21 \%$ of peak area, followed by $Y$-terpinene (15.07\%), o-cymene (9.75\%), (E)-caryophyllene $(9.25 \%)$ and $\alpha$-trans-bergamotene $(5.29 \%)$, respectively. Monoterpenes were predominant, both in number of peaks (14 compounds) and area percentage, comprising $76.88 \%$ of the total area. However, 9 sesquiterpenes were identified, adding up to $18.90 \%$ of the total area. A total of 9 oxygenated compounds were identified, constituting $50.23 \%$ of the total peak area. For the essential oil, $96.86 \%$ of the chromatogram was accounted for 25 identified compounds, 17 of which were present in all chromatographic analyses, including the four HS-SPME methods.

The SPME fiber with CAR/PDMS coating showed the most distinct composition, being o-cymene the most abundant compound (29.13\%), followed by carvacrol $(15.92 \%)$ and (E)-caryophyllene (13.16\%). Conversely, PDMS, PDMS/DVB and DVB/CAR/PDMS fiber profiles exhibited carvacrol as the major component with 27.38, 34.50 and $34.09 \%$ of total area, respectively. The extractions with PDMS/DVB and DVB/CAR/PDMS fibers resulted in the most similar composition in terms of: the most abundant compounds, area percentage and number of identified compounds from each category. PDMS/DVB fiber extracted $64.32 \%$ of monoterpenes, $30.93 \%$ of sesquiterpenes and $41.11 \%$ of oxygenated compounds, whilst DVB/CAR/PDMS fiber extracted for the same categories a total of $67.22,23.88$ and $43.33 \%$, respectively. PDMS fiber showed an increased extraction of sesquiterpenes $(42.09 \%)$ and a decrease in the area percentage of the other two groups. CAR/PDMS fiber showed a decrease in monoterpenes and oxygenated compounds and an intermediary area percentage of sesquiterpenes, both fibers result in comparison with the PDMS/DVB and DVB/CAR/PDMS fiber extractions.

The compounds identified in the essential oil (Table 1) are similar to the ones reported in other investigations conducted with $P$. amboinicus plants growing in Brazil. For example, Bezerra et al. (2017) and Santos et al. (2015) indicated that carvacrol, $\mathrm{Y}$-terpinene, cymene, caryophyllene and $\alpha$-trans-bergamotene were major components of $P$. amboinicus essential oil. Similarly, besides borneol, all the compounds identified in the essential oil were present in at least one of the four different HS-SPME analyses, supporting the applicability of this technique in studies of essential oil-bearing plants. Noguchi and Amaki (2016) reported the composition of fresh leaf volatiles of $P$. amboinicus under different light treatments using PDMS/DVB fiber and indicated limonene, linalool and germacrene $D$ as three of the major components, none of which were identified in our analysis. The first and only comparison between fibers for HS-SPME analysis of $P$. amboinicus leaf volatiles was realized by Phungpanya et al. (2012) employing the same four fiber coatings. Thymol carbamate and 2-(7Z)bisaboladien-4-ol were found to be the major components and forty-five other compounds were reported for the species. Most of the compounds reported, including the two major components, were below detection limit in the present study. This discrepancy in the chemical composition may be a consequence of environmental factors or genetic variation, seeing that individuals grown in different countries are being compared (Gobbo-Neto and Lopes, 2007). Further research on the effect of genetic variation and growth conditions on the composition of $P$. amboinicus leaf volatiles is clearly needed.

The selection of an effective fiber in order to study a medicinal or aromatic plant is one of the main tasks when developing a SPME method (Belliardo et al., 2006). Many fiber assemblies are commercially available and amongst the factors that influence the choice of fiber, interaction between polymeric coating and analytes as a result of polarity affinity is of fundamental importance. The fibers in this study ranged in polarity: from a non-polar PDMS fiber, low polarity CAR/PDMS, medium polarity DVB/CAR/PDMS, to the most polar fiber tested PDMS/DVB (Kataoka et al., 2000). PDMS fiber extractions were characterized by high area percentage of sesquiterpenes, mainly sesquiterpene hydrocarbons such as $\alpha$-trans-bergamotene and $\alpha$-humulene, a lowpolarity to non-polar class of compounds, while CAR/PDMS extractions showed an increase in area percentage of a few components such as (E)-2-hexenal, 1-octen-3-ol, o-cymene and (E)- $\beta$-farnesene. These results indicate that both PDMS and CAR/PDMS fiber extractions presented very distinct GC-MS profiles when compared to the essential oil composition. Therefore, PDMS and CAR/PDMS fibers may be suitable for targeted analysis of specific compounds or a class of low polarity compounds.

Besides evaluation of target compounds, another approach in phytochemistry is untargeted analysis of chemical compounds, that is, a qualitative analysis of the greatest number of compounds as possible (Canuto et al., 2018). PDMS/DVB fiber presented the highest area coverage and number of identified compounds, supporting its use for such an investigation. Furthermore, DVB/CAR/PDMS fiber extraction resulted in the most similar chemical profile when compared to essential oil 


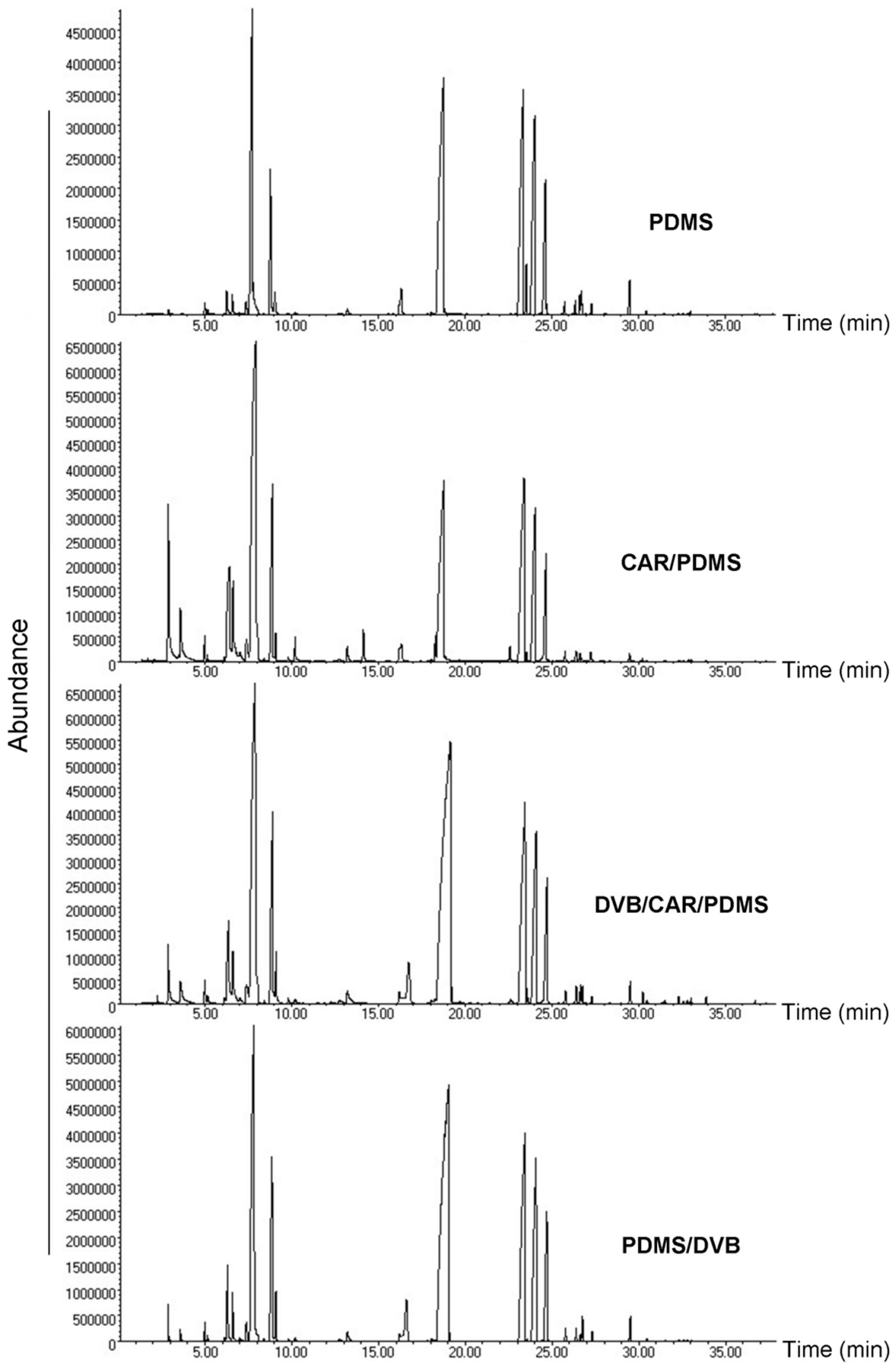

Figure 1. HS-SPME/GC-MS analysis of Plectranthus amboinicus (Lour.) Spreng. leaf volatiles using the following fibers: PDMS $(100 \mu \mathrm{m})$, CAR/PDMS $(75 \mu \mathrm{m})$, DVB/CAR/PDMS $(50 / 30 \mu \mathrm{m})$ and PDMS/DVB $(65 \mu \mathrm{m})$. 
Table 1. Chemical composition of Plectranthus amboinicus (Lour.) Spreng. essential oil via GC-MS and leaf volatiles via HS-SPME/GC-MS.

\begin{tabular}{|c|c|c|c|c|c|c|}
\hline \multirow{2}{*}{$\mathbf{R} \mathbf{I}^{\mathbf{A}}$} & \multirow{2}{*}{ Compound } & \multicolumn{5}{|c|}{ Area (\%) } \\
\hline & & Essential oil & PDMS & CAR/PDMS & DVB/CAR/PDMS & PDMS/DVB \\
\hline 801 & Hexanal & --- & --- & --- & 1.33 & 0.44 \\
\hline 846 & (E)-2-Hexenal & 0.1 & --- & 2.47 & 1.04 & 0.18 \\
\hline 924 & a-Thujene & 0.57 & 0.35 & 0.38 & 0.43 & 0.26 \\
\hline 932 & a-Pinene & 0.2 & 0.16 & 0.1 & 0.2 & 0.10 \\
\hline 946 & Camphene & 0.03 & -- & 0.01 & 0.04 & 0.01 \\
\hline 969 & Sabinene & 0.07 & 0.03 & 0.1 & 0.1 & 0.05 \\
\hline 974 & 1-Octen-3-ol & 0.98 & 0.91 & 5.05 & 3.02 & 2.14 \\
\hline 988 & Myrcene & --- & --- & --- & 1.49 & 0.91 \\
\hline 1002 & a-Phellandrene & 0.33 & 0.07 & 0.47 & 0.24 & 0.13 \\
\hline 1008 & $\delta$-3-Carene & 0.07 & --- & --- & --- & 0.03 \\
\hline 1014 & $\alpha$-Terpinene & 2.63 & 0.54 & 0.99 & 0.73 & 0.58 \\
\hline 1022 & o-Cymene & 9.75 & 17.14 & 29.13 & 20.47 & 18.65 \\
\hline 1054 & $\mathrm{y}$-Terpinene & 15.07 & 4.8 & 6.16 & 5.89 & 5.77 \\
\hline 1086 & Terpinolene & 0.08 & --- & 0.1 & 0.12 & 0.06 \\
\hline 1165 & Borneol & 0.08 & --- & --- & --- & --- \\
\hline 1174 & Terpinen-4-ol & 0.76 & 0.26 & 0.47 & 0.63 & 0.43 \\
\hline 1248 & Thymoquinone & --- & 1.54 & 1.12 & 2.68 & 2.70 \\
\hline 1289 & Thymol & 0.06 & 0.18 & 0.1 & 0.13 & 0.15 \\
\hline 1298 & Carvacrol & 47.21 & 27.38 & 15.92 & 34.09 & 34.50 \\
\hline 1417 & (E)-Caryophyllene & 9.25 & 19.91 & 13.16 & 11.73 & 15.06 \\
\hline 1432 & $\alpha$-trans-Bergamotene & 5.29 & 13.24 & 7.79 & 7.28 & 9.66 \\
\hline 1445 & epi- $\beta$-Santalene & 0.03 & --- & -- & --- & 0.07 \\
\hline 1452 & a-Humulene & 2.64 & 6.47 & 3.8 & 3.68 & 4.62 \\
\hline 1454 & (E)- $\beta$-Farnesene & 0.11 & -- & 0.21 & --- & --- \\
\hline 1500 & a-Muurolene & 0.14 & 0.37 & 0.3 & 0.37 & 0.26 \\
\hline 1505 & $\beta$-Bisabolene & 0.25 & 0.66 & 0.06 & 0.28 & 0.48 \\
\hline 1521 & $\beta$-Sesquiphellandrene & 0.14 & 0.32 & -- & 0.14 & 0.23 \\
\hline \multirow[t]{5}{*}{1582} & Caryophyllene oxide & 1.05 & 1.12 & 0.19 & 0.41 & 0.57 \\
\hline & Monoterpenes & $76.88(14)$ & $52.46(11)$ & $55.05(13)$ & $67.22(14)$ & $64.32(15)$ \\
\hline & Sesquiterpenes & $18.90(9)$ & $42.09(7)$ & $25.51(7)$ & $23.88(7)$ & $30.93(8)$ \\
\hline & ygenated compounds & $50.23(7)$ & $31.39(6)$ & $25.32(7)$ & $43.33(8)$ & $41.11(8)$ \\
\hline & al identified compounds & $96.86(25)$ & $95.46(19)$ & $88.07(22)$ & $96.49(24)$ & $98.01(26)$ \\
\hline
\end{tabular}

${ }^{A}$ Retention indices obtained from Adams (2007).

Numbers in bold font indicate the five major components, in terms of area percentage, for each analysis; numbers between parentheses indicate number of compounds representing the categories and three hyphens (---) represent values below detection limit.

composition and extracted more unidentified components with high retention time, which may be important in chemometric comparisons between chemical profiles. PDMS/DVB and DVB/CAR/PDMS fiber extractions differed qualitatively, only due to the presence of $\delta$-3carene and epi- $\beta$-santalene in the PDMS/DVB fiber extraction ( $0.1 \%$ of identified compounds). These results are partially in agreement with Phungpanya et al. (2012), suggesting that DVB/CAR/PDMS is the most effective of the four evaluated fibers for untargeted analysis of $P$. amboinicus leaf volatiles. However, we found that PDMS/DVB fiber may be used for the same purpose and two more compounds (i.e. $\delta$-3-carene and epi- $\beta$ - santalene) were identified with this fiber.

\section{CONCLUSION}

HS-SPME coupled to GC-MS was confirmed to be a simple and rapid method of analysis for Plectranthus amboinicus volatiles. The major components found in headspace and essential oil were carvacrol, o-cymene, (E)-caryophyllene and $\alpha$-trans-bergamotene. DVB/CAR/PDMS fiber extraction was similar to essential oil composition while PDMS/DVB extraction resulted in the highest area coverage and number of identified 
components, both fibers being the most suitable in an untargeted analysis of volatiles. On the other hand, PDMS and CAR/PDMS fibers may be suitable for targeted analysis of low polarity compounds or classes of compounds.

\section{ACKNOWLEDGEMENTS}

This study was financed in part by the Coordenação de Aperfeiçoamento de Pessoal de Nível Superior - Brasil (CAPES) - Finance Code 001. The authors would like to thank Dr. Marcos Nogueira Eberlin for the use of the GCMS and the other members from the ThoMSon Laboratory of Mass Spectrometry for technical advice, and the Committee for the Postgraduate Program in Plant Biology (University of Campinas) for financial support. Alexandra C.H.F. Sawaya would like to thank the National Council for Scientific and Technological Development (CNPq) for a grant.

\section{REFERENCES}

Adams RP, 2007. Identification of Essential Oil Components by Gas Chromatography/Mass Spectrometry. Allured Publishing Co. Carol Stream, Illinois.

Arumugam G, Swamy MK, Sinniah UR, 2016. Plectranthus amboinicus (Lour.) Spreng: botanical, phytochemical, pharmacological and nutritional significance. Molecules, 21(4): 369.

Belliardo F, Bicchi C, Cordero C, Liberto E, Rubiolo P, Sgorbini B, 2006. Headspace-solid-phase microextraction in the analysis of the volatile fraction of aromatic and medicinal plants. J Chromatogr Sci, 44(7): 416-429.

Bezerra RCF, Oliveira Neto FB, Silva FFM, Bertini LM, Alves LA, 2017. Seasonal effect in essential oil composition and antioxidant activity of Plectranthus amboinicus leaves. Biosci J, 33(6): 1608-1616.

Camelo ALM, Oliveira FC, Correia FT, Barbosa FG, Mafezoli J, Diogenes ICN, Araujo AJ, Costa-Lotufo LV, Longhinotti E, 2019. Discrimination of VOCs of the Plectranthus grandis by hydrodistillation, HS-SPME and cytotoxic activity. Ind Crop Prod, 127: 225-231.

Canuto GAB, da Costa JL, da Cruz PLR, de Souza ARL, Faccio AT, Klassen A, Rodrigues KT, Tavares MFM, 2018. Metabolomics: Definitions, state-of-the-art and representative applications. Quim Nova, 41(1): 75-91.

Charles DJ, Simon JE, 1990. Comparison of extraction methods for the rapid determination of essential oil content and composition of basil. $J$ Amer Soc Hort Sci, 115(3): 458-462.

Chiu YJ, Huang TH, Chiu CS, Lu TC, Chen YW, Peng WH, Chen CY, 2012. Analgesic and anti-inflammatory activities of the aqueous extract from Plectranthus amboinicus (Lour.) Spreng. both in vitro and in vivo. Evid Based Complement Alternat Med, 2012: 1-11.

Codd LE, 1975. Plectranthus (Labiatae) and allied genera in Southern Africa. Bothalia, 11(4): 371-442.

da Costa JGM, Pereira CKB, Rodrigues FFG, 2010. Chemical composition, antibacterial and fungicidal activities of leaf oil of Plectranthus amboinicus (Lour.) Spreng. Journal of Essential Oil Research. 22(2): 183-185.

El-Sakhawy FS, Kassem HA, El-Gayed SH, Mostafa MM, 2018. Headspace solid phase microextraction analysis of volatile compounds of the aerial parts and flowers of Plectranthus neochilus Schltr. and Salvia farinacea Benth. J Essent Oil Bear PI, 21(3): 674686.
Gavaric N, Mozina SS, Kladar N, Bozin B, 2015. Chemical profile, antioxidant and antibacterial activity of thyme and oregano essential oils, thymol and carvacrol and their possible synergism. J Essent Oil Bear PI, 18(4): 1013-1021.

Gobbo-Neto L, Lopes NP, 2007. Medicinal plants: Factors of influence on the content of secondary metabolites. Quim Nova, 30(2): 374-381.

Kataoka H, Lord HL, Pawliszyn J, 2000. Applications of solid-phase microextraction in food analysis. J Chromatogr A, 880(1-2): 35-62.

Lee JH, Kim YG, Lee J, 2017. Carvacrol-rich oregano oil and thymolrich thyme red oil inhibit biofilm formation and the virulence of uropathogenic Escherichia coli. J Appl Microbiol, 123(6): 1420-1428.

Lima MAA, Oliveira FFM, Gomes GA, Lavor PL, Santiago GMP, Nagao-Dias AT, Arriaga MC, Lemos TLG, Carvalho MG, 2011. Evaluation of larvicidal activity of the essential oils of plants species from Brazil against Aedes aegypti (Diptera: Culicidae). Afr J Biotechnol, 10(55): 11716-11720.

Lorenzi H, Matos FJA, 2008. Plantas medicinais no Brasil: nativas e exóticas. 2nd Ed. Instituto Plantarum de Estudos da Flora. Nova Odessa, São Paulo.

Lukhoba CW, Simmonds MSJ, Paton AJ, 2006. Plectranthus: A review of ethnobotanical uses. J Ethnopharmacol, 103(1): 1-24.

Noguchi A, Amaki K, 2016. Effect of light quality on the growth and essential oil production in Mexican mint. Acta Hortic, 1134: 239-244.

Passinho-Soares HC, Meira PR, David JP, Mesquita PRR, do Vale AE, Rodrigues FD, Pereira PAD, de Santana JRF, de Oliveira FS, de Andrade JB, David JM, 2013. Volatile organic compounds obtained by in vitro callus cultivation of Plectranthus ornatus Codd. (Lamiaceae). Molecules, 18(9): 10320-10333.

Phungpanya C, Thongpoon C, Pripdeevech P, Machan T, 2012. Analysis of aroma volatiles from fresh leaves of Plectranthus amboinicus using solid-phase microextraction (SPME) technique. Pure and Applied Chemistry International Conference 2012, Jan. 1113, Chiang Mai, Thailand, pp: 1670-1672.

Santos NO, Mariane B, Lago JH, Sartorelli P, Rosa W, Soares MG, da Silva AM, Lorenzi H, Vallim MA, Pascon RC, 2015. Assessing the chemical composition and antimicrobial activity of essential oils from Brazilian plants - Eremanthus erythropappus (Asteraceae), Plectrantuns barbatus, and P. amboinicus (Lamiaceae). Molecules, 20(5): 8440-8452.

Senthilkumar A, Venkatesalu V, 2010. Chemical composition and larvicidal activity of the essential oil of Plectranthus amboinicus (Lour.) Spreng against Anopheles stephensi: a malarial vector mosquito. Parasitol Res, 107(5): 1275-1278.

Singh G, Singh OP, Prasad YR, Lamposona MP, Catalan C, 2002 Studies on essential oils. Part 33. Chemical and insecticidal investigations on leaf oil of Coleus amboinicus (Lour). Flavour Fragr J, 17(6): 440-442.

Swamy MK, Arumugam G, Kaur R, Ghasemzadeh A, Yusoff MM, Sinniah UR, 2017. GC-MS based metabolite profiling, antioxidant and antimicrobial properties of different solvent extracts of malaysian Plectranthus amboinicus leaves. Evid Based Complement Alternat Med, 2017: 1-10.

von Oppen S, Masuh H, Licastro S, Zerba E, Gonzales-Audino P, 2015. A floral-derived attractant for Aedes aegypti mosquitoes. Entomol Exp Appl, 155(3): 184-192.

Zhang Z, Pawliszyn J, 1993. Headspace solid-phase microextraction. Anal Chem, 65(14): 1843-1852.

Citation: Pinheiro GP, Galbiatti MI, Carneiro MJ, Sawaya ACHF, 2019. Comparison of four different solid-phase microextraction fibers for analysis of Plectranthus amboinicus (Lour.) Spreng. leaf volatiles. Adv Med Plant Res, 7(2): 38-43. 